\title{
A construção social do prazer
}

\section{O orgasmo e o Ocidente: uma história do prazer do século XVI a nossos dias.}

MUCHEMBLED, Robert.

São Paulo: Martins Fontes, 2007. 377 p.

(Tradução de Monica Stahel do original L'Orgasme et l'Occident: une histoire du plaisir du XVle siècle à nos jours. Paris: Seuil, 2005).

Traduzido no Brasil dois anos após seu Iançamento na França, O orgasmo e o Ocidente é o segundo livro de Robert Muchembled publicado no país, que começa a receber a produção de um autor destacado na historiografia francesa contemporânea. Voltada ao percurso do prazer ao longo dos últimos cinco séculos nos discursos religioso, literário e político, essa obra analisa comparativamente França e Inglaterra e, no século XX, os desdobramentos da revolução sexual nos Estados Unidos, enfatizando o impacto da volúpia nas mentalidades.

Seguindo sua análise em Uma história do Diabo,' de como o medo do Maligno construiu uma identidade coletiva da Europa ocidental, estimulada pela descoberta do Novo Mundo e pelas reformas religiosas, nessa nova obra Muchembled explora como o prazer, seja em sua busca, seja em sua repressão, não apenas impulsionou indivíduos, mas também dinamizou os países abordados. Observa-se, após cada voga repressiva, um período de busca pela libertação das amarras impostas e uma conseqüente revitalização intelectual, e desse desequilíbrio entre sublimação do prazer e hedonismo ressalta-se a construção dos comportamentos.

Diferentemente de Michel Foucault, ${ }^{2}$ o autor foca nos meados do século $\mathrm{XVI}$, a partir da conjunção de esforços entre Igreja e Estado no sentido de controlar os corpos e disciplinar as consciências de seus sujeitos, uma intensa repressão do prazer, recuada apenas a partir da década de 1960. Seguindo essa evolução, a obra divide-se em três partes, correspondentes à concepção da sexualidade no mundo ocidental: séculos XVl e XVII, com o binômio prazer e dor; do século XVIII a 1960, quando, após uma "liberalização dos costumes" nos primeiros cem anos, manifesta-se um retrocesso com o puritanismo; e a partir de 1960, quando o autor dedica-se à contraposição entre um hedonismo europeu e a continuidade do modelo repressor nos Estados Unidos.

A primeira fase, marcada pela acentuada desconfiança em relação ao feminino e intensamente influenciada pelo discurso religioso, apresenta no extremo da suspeição as pretensas bruxas. Observa-se nas transcrições dos interrogatórios uma sexualidade profundamente deturpada, traduzida em coitos dolorosos com íncubus (demônios masculinos) e esterilidade. A ansiedade provocada pelo corpo feminino, cuja luxúria é disseminada na iconografia, pode ser também observada no interesse suscitado pelas dissecações, quando são buscadas respostas à natureza considerada fria e úmida das mulheres, além de sua vinculação ao pecado original.

Paralelamente a esse cenário, delimita-se a imagem da esposa centrada na procriação sem recurso ao prazer dentro do casamento que, por si só, é o destino dos incapazes de viver virtuosamente. No início do século XVII, os cânones anglicanos e católicos quanto ao casamento refletem uma mesma intenção ordenadora e, em ambos os lados do canal, intensifica-se a vigilância moral nas paróquias, revelando a importância do policiamento através do olhar externo previamente ao recalcamento. Nesse sentido, a própria exigência da confissão desde o Concílio de Trento contribui decisivamente para o enraizamento da culpabilidade nos católicos, que têm suas práticas sexuais questionadas pelos confessores.

No entanto, apoiado em fontes jurídicas francesas e inglesas, o autor revela que o rigor moral apregoado pelos discursos eclesiásticos não se enraizou nas comunidades imediata e intensamente segundo o apelo dos reformadores. Assim, ressalta-se a necessidade de distinção entre os discursos e as práticas, considerandose, sobretudo, que uma rígida normatização moral é lentamente difundida a partir do grupo em que se difunde primariamente, para apenas paulatinamente atingir outros escalões sociais.

Muchembled dá novos contornos à tese de Max Weber de que o protestantismo traçou os rumos do capitalismo nascente, pois seria no esforço em direção ao autocontrole e à depura- 
ção do sexo que reside a originalidade da Europa ocidental moderna. Seguindo o pensamento de Norbert Elias sobre a civilização dos costumes, ${ }^{3}$ o historiador francês enfatiza o papel desse processo no campo afetivo e na inibição da volúpia, para reforçar a teoria da repressão sexual enquanto um motor ocidental.

O enquadramento juvenil é, para o autor, essencial nesse cenário, e os adolescentes constituem um grupo socialmente definido ${ }^{4}$ muito antes do adequamento de sua sexualidade delimitado por Foucault no século XIX. Em meio à reforma dos costumes e ao avanço da moralização, torna-se indispensável restringir a sexualidade dos jovens que, ademais, vêem progressivamente seus círculos e práticas de solidariedade reduzidos. Assim, encontramos um propulsor fundamental na delimitação das práticas lícitas que buscam o prazer.

Nos grandes centros, ao mesmo tempo que se exalta o modelo conjugal para procriação, entrega-se o prazer à marginalidade, disseminando-se junto às práticas extraconjugais as DST e a ilegitimidade. Assim, evidencia-se que o prazer, mesmo obtido dentro do casamento, condena a mulher, pois está relacionado às prostitutas. O modelo de masculinidade difundido acaba por remodelar a própria relação entre homens, pois o fantasma da homossexulidade começa lentamente a se materializar na esfera pública, passando mesmo a amizade masculina à suspeição. Disseminamse dicursos contra o "vício solitário", e nessa campanha Maurice Daumas ressalta a intenção de se eliminar a sodomia através da perseguição à masturbação e do enfraquecimento dos laços masculinos. $^{5}$

Constata-se que, embora no campo discursivo o prazer não deva ser almejado, sob pena da perdição eternal, ele não deixa de ser explorado e encontra então novos meios de expressão que se chocam com a ortodoxia. $\mathrm{Na}$ época barroca, o orgasmo ou 'pequena morte' situa-se paradoxalmente tanto no campo demoníaco quanto, para escritores como Corneille, no campo místico. Em meio à disseminação dos manuais de boa conduta, o lançamento, em 1655, do célébre manual de conduta erótica L'École des filles, ${ }^{6}$ cuja abordagem do orgasmo feminino virá a chocar os espíritos decorosos - sem deixar de ser um sucesso editorial -, aponta para uma 'virada pornográfica', observada na França e na Inglaterra.

Chocando-se com a acentuação do disciplinamento nas grandes cidades e a própria concentração do poder real, a pornografia manifesta-se em meados do século XVII como um exutório, pois, nas palavras do autor, "é justamente o jogo entre a autoridade e a transgressão que lhe dá vida e lhe confere um status cultural importante, como testemunho da discordância entre os princípios e as realidades" (p. 158). Contudo, apesar de sua indecorosidade, a pornografia nesse momento endossa os papéis sociais atribuídos aos gêneros, sem questionar-Ihes a validade.

Os libertinos inauguram então o segundo período abordado pelo autor, no qual as relações, outrora embasadas em prescrições religiosas e judiciárias, além do controle familiar, são refundadas sobre a razão, o saber médico e uma nova percepção do amor. O princípio da inferioridade feminina encontra a partir desses elementos duas expressões: a esposa, que deve ser confinada ao lar para a proteção de si mesma, e a perdida, conjunção das faces negativas até então projetadas sobre todas as mulheres. O duplo padrão prega a separação entre procriação e prazer para o exclusivo benefício masculino, fundamentada não mais no temor das penas infernais, mas na razão médica.

A disseminação do amor romântico até as regiões mais distantes dos grandes centros a partir de meados do século XVIII obtém alguns resultados importantes analisados pelo autor: crescem as separações por incompatibilidade na Inglaterra no mesmo período e diminuem drasticamente os processos por traição, pois a infidelidade passa a perturbar a esfera privada mais do que a colocar em causa a estrutura social em questão. No entanto, como Anthony Fletcher ${ }^{7}$ já apresentou anteriormente, a concordância dos cônjuges esconde uma armadilha para as mulheres que, ao dar seu aval na união, não deixam de se submeterem aos maridos, mas o fazem através do consentimento àquele que, em teoria, foi por elas escolhido, e recebem continuamente um modelo comportamental adequado através de uma literatura específica.

O puritanismo ultrapassa os limites do reinado de Vitória (1837-1901) e, fomentado pelos filósofos, é adotado pelas burguesias enquanto um modelo de vida diferenciador dos demais grupos sociais. A necessidade despertada de "triunfo sobre o vício", do qual despreende-se o autocontrole, conduz a um recalque dos prazeres, e Muchembled enfatiza o processo de elevação do constrangimento, decorrente da sublimação dos instintos pelo habitus, que situa o limiar da transição rumo à inculpação pessoal. 
Não admira, portanto, que nesse cenário desenvolva-se a Psicanálise, para desenraizar os traumas gerados pela repressão sexual sofrida desde a infância. Do mesmo modo, com o início da transformação das mentalidades vitorianas, também as autoridades médicas começam a manifestar-se mais expressamente sobre as "anormalidades" como o homossexualismo, o sadismo e o masoquismo, e a masturbação cede espaço nos debates.

Esse processo, no entanto, não se desenrola sem reclames dos moralistas, cuja concepção de mundo fundamentada no duplo padrão começa a ruir com a quebra de tabus, o que afeta notadamente o desequilíbrio da relação entre os gêneros nos grupos trabalhadores. A lei sobre o divórcio, em 1884 na França e em 1920 na Inglaterra, assinala uma ruptura primordial nas estruturas sociais patriarcais, que recebem contínuos abalos em suas fundações. Ademais, os anos seguintes à Primeira Guerra Mundial, com a busca de alívio das tensões, são decisivos na proliferação de práticas voltadas ao prazer e de grupos marginalizados.

Muchembled atribui um papel capital na esteira das transformações à publicação, em 1948 , do primeiro relatório de Alfred C. Kinsey, um anúncio da era de libertação feminina do que o autor classifica como "tirania da sexualidade obrigatoriamente fecundadora" (p. 308). Apesar da importância inegável das etapas seguintes, tendo em vista o longo período histórico abordado, elas compreendem um espaço proporcionalmente reduzido na obra: a pílula anticoncepcional criada na década de 1950 e difundida a partir da década seguinte e, na década de 1970, o avanço das demandas e conquistas feministas e, mais lentamente, homossexuais, além do peso da legalização do aborto pela Suprema Corte Americana em 1973, elementos essenciais no progresso em direção à igualdade dos gêneros, o que inclui a busca pelo prazer.

A diferença de mentalidade entre os dois pólos analisados, a Europa ocidental e os Estados Unidos do século XX, aponta não somente uma diferença de valores fundada sobre distintas bases culturais, mas também diferenças internas. Mesmo caracterizando a maior permissividade erótica européia, o autor não deixa de considerar as peculiaridades próprias à Europa nórdica e à França, além da divisão americana entre o Sul tradicionalista e os estados do Nordeste e Nova York. E é o individualismo em marcha nessas áreas que antecipa a liberdade sexual, lembrando-se ainda que, apesar dos imperativos do mercado, que ditam a atual expansão do erotismo, tradições seculares não são repentinamente obliteradas, e não deixarão de influenciar as gerações futuras na definição de seus papéis

O autor finaliza discorrendo sobre questionamentos essenciais no início do novo século, quando mais uma vez os jovens do sexo masculino se vêem atingidos pelas mudanças, situandose no limiar entre uma secular tradição machista e as exigências de respeito à igualdade pelas mulheres. Sobre as ruínas do patriarcalismo, minorias outrora marginalizadas conquistam seu direito à existência aberta e à cidadania, mas são sobretudo as mulheres as beneficiadas pela promoção do prazer, libertas da tutela patriarcal e da procriação obrigatória.

Definindo a sexualidade como "a chave da civilização moderna" (p. 346), Muchembled se propõe a trilhar um percurso percorrido por Michel Foucault, no qual confessamente se inspira, mas que com ele não se estagnou. Mais do que discorrer sobre a historicidade do prazer nos últimos cinco séculos, de modo inovador Muchembled desenvolve uma teoria da sexualidade explicativa da expansão européia na Modernidade.

\section{Notas}

${ }^{1}$ MUCHEMBLED, 2001.

${ }^{2}$ FOUCAULT, 1976.

${ }^{3}$ ELIAS, 2003.

${ }^{4} \mathrm{O}$ autor trabalha mais especificamente o assunto em MUCHEMBLED, 1988.

${ }^{5}$ DAUMAS, 2007, p. 327.

6 O livro apresenta a educação sexual de Fanchon por sua prima, Susanne, com detalhes de sua iniciação e busca pelo prazer.

${ }^{7}$ FLETCHER, 1995.

\section{Referências bibliográficas}

DAUMAS, Maurice. Au Bonheur des Mâles. Adultère et cocuage à la Renaissance 1400-1650. Paris: A. Colin, 2007.

ELIAS, Norbert. La Civilisation des mœurs. Paris: Pocket, 2003.

FLETCHER, Anthony. Gender, Sex \& Subordination in England 1500-1800. New Haven, London: Yale University Press, 1995.

FOUCAULT, Michel. Histoire de la Sexualité. Paris: Gallimard, 1976. t. 1.

MUCHEMBLED, Robert. L'invention de l'homme moderne. Cultures et sensibilités en France du XVe au XVIII' siècle. Paris: Fayard, 1988.

Uma história do Diabo: séculos XII-XX. Rio de Janeiro: Bom Texto, 2001.

Silvia Liebel Université Paris XIII 